\title{
Lectores de bibliotecas vs una biblioteca de lector
}

\author{
Rubén Darío Flórez Arcila* \\ Universidad Nacional de Colombia, Colombia \\ florezaruben@gmail.com
}

\section{Resumen}

En este artículo se argumenta desde el concepto de semiósfera la hipótesis de que, en las tres primeras décadas del siglo XX en Colombia, las prácticas sociales en torno al libro y los significados o representaciones sobre la función del libro, la biblioteca, las librerías y los lectores se constituyeron en Colombia a partir de la oposición lector selecto de una biblioteca de élite vs lectores de bibliotecas públicas. Se problematiza este sistema: biblioteca, librería, lector, a partir de tres preguntas ¿Cuál era la valoración del lugar de la traducción? ¿Qué función desempeñaba el libro en los intercambios urbanos? ¿Qué tipo de relación se daba entre librerías, bibliotecas y lectores en el contexto de la Bogotá de comienzos del siglo XX?

Palabras clave: Biblioteca, comunicación, traducción, lector, Colombia. Semiósfera urbana.

\section{Library Readers vs. Reader Library}

\begin{abstract}
This article argues for the concept of the semiosphere the hypothesis that in the first three decades of the twentieth century in Colombia, social practices around the book and the meanings or representations about the function of the book, library, bookstores and Readers were constituted in Colombia from the select reader opposition of an elite library vs. readers of public libraries. This system is problematized: library, bookstore, reader, from three questions What was the assessment of the place of translation? What role did the book play in urban exchanges? What kind of relationship was found between libraries, libraries and readers in the context of Bogota in the early twentieth century?
\end{abstract}

Keywords: Library, communication, translation, reader, Colombia. Urban semiosphere.

* Profesor Asociado, traductor, filólogo, Magister en ciencias filológicas, lingüista y PhD (Candidato) en culturología. 
“Cuando se proclamó que la Biblioteca abarcaba todos los libros, la primera impresión fue de extravagante felicidad. Todos los hombres se sintieron señores de un tesoro intacto y secreto. No había problema personal o mundial cuya solución no existiera en algún hexágono" J. L. Borges. La Biblioteca de Babel.

\section{A la inspirada Ramadinova que en Moscú me enseñó el camino al Gran Dante}

\section{Introducción}

Para desarraigar ciertos lugares comunes que existen en Colombia sobre el libro, el lector, la librería y las bibliotecas, producidos por la práctica social, individual y de grupos pertenecientes a un espacio histórico de tiempo preciso, es necesario examinar, apoyándose en evidencias documentadas, la manera como se fueron constituyendo las nociones de lector y biblioteca en nuestro país. Sólo tomando conciencia de los prejuicios y convicciones colombianas alrededor del libro, las bibliotecas y los lectores podemos imaginar una nueva situación para los lectores y las bibliotecas a tono con las exigencias de establecimiento de una cultura moderna, hacia la que nuestro país no ha dado aún el paso definitivo.

En esta comunicación voy a compartir algunos hallazgos y reflexiones personales acerca de la fabricación de una práctica colombiana sobre el significado ${ }^{1}$ del libro, de la biblioteca y el lector. Esta noción colombiana, a mi juicio, sigue influyendo las estrategias para la formación de lectores y de su amor por los libros. En buena medida impiden el crecimiento de una comunidad masiva de lectores que supere la actual naturaleza de elite de la comunidad lectora colombiana.

La situación colombiana sobre la lectura y el libro puede caracterizarse como de composición y representación elitista del lector. Esta realidad histórica y social colombiana de elite se refiere al número tan pequeño de lectores consumados del país; a aquellos que en Colombia consideran el libro como punto de referencia, de formación intelectual, estrategia cognitiva cotidiana, como medio de diálogo, o sea, de encuentro consigo mismo y con otros; más allá de una exigencia exterior laboral, escolar o técnica, que suele ser esporádica o vinculada exclusivamente al periodo de formación escolar y o universitaria.

La exposición que sigue no otorga mayor responsabilidad, por la ausencia de una masiva comunidad de lectores, al crecimiento de los medios audiovisuales, que a menudo suelen señalarse como los responsables de la falta de interés de los colombianos hacia la lectura.

Dicha conjetura, a mi modo de ver no sabe examinar el conjunto de condiciones históricas y culturales que fueron configurando en Colombia la identidad social e individual del lector, además de los prejuicios y opiniones colombianos sobre el libro. A ésta dedicaré mi exposición.

Los dos conceptos que me permitirán arrojar una luz sobre realidades socioculturales productoras de una mentalidad y unas prácticas sobre el libro, los he llamado provisionalmente "el espacio de la biblioteca de un lector" y "el espacio de los lectores de bibliotecas". Ambos términos vinculan un concepto sobre diferentes contextos culturales y sociales de la relación con el libro, un significado sobre la biblioteca y una apreciación o menosprecio por la noción de masividad, comunicación, traducción y reproducción de la práctica lectora, por tanto de la expansión de los lectores y de las interpretaciones. La noción y realidad de élites de lectores trae como hecho concomitente la realidad de interpretaciones canónicas o autorizadas. La masividad de los lectores en cierto modo las fragmenta, permite relativizar su autoridad.

1 ¿Qué es el significado de un término? Desde el punto de vista semiótico no puede ser otra cosa que una unidad cultural. En toda cultura una "unidad" es, algo que está definido culturalmente y definido como entidad. Puede ser una persona, un lugar, una cosa, un sentimiento, una situación, una fantasía, una alucinación, una esperanza o una idea. Eco, 1999,71. 
Para la noción de espacio del lector, del libro y de la biblioteca, para entender su carácter indisoluble y orgánico, en el sentido de que una comprensión de la lectura lleva a un tipo de relación con el libro, y a una representación sobre qué se considera libro; así como la interpretación sobre el carácter del lector lleva a una consideración de orden teórico y práctico sobre la naturaleza de la biblioteca, emplearé el concepto de Iuri Lotman, el ilustre pensador semiótico de Tallin, algunos de cuyos textos he traducido al castellano de Colombia. Adopto la idea de Lotman que considera la comunicación cultural esencialmente como un modo de traducción. Este concepto es el de semiósfera ${ }^{2}$.

Lotman considera que el ser humano está inmerso en un continuum de textos, lenguas y códigos (actualmente considero también que los dispositivos teconológicos de archivos on line, $\mathrm{dvd}$, cd y celulares hacen parte de este continuum semiótico). Este continuum que forma nuestro entorno inmediato semiótico, como si se tratara de una especie de "atmósfera" semiótica, permite tener un tipo de memorias culturales, realizar la comunicación entre individuos y determina nuestra relación cognitiva y práctica con la memoria cultural como mecanismo de formación de los sentidos.

Todo texto requiere de unos códigos de interpretación, de una traducción que permite su comunicación. Dicho de otra manera, el principio fundamental de formación de los sentidos culturales, es que no hay un texto que pueda comunicarse por sí mismo, éste debe ser traducido. Ésta afirmación se extiende tanto a los textos provenientes de culturas o semiosferas distintas como para los textos y su comunicación dentro de una cultura dada. Hay traducción intercultural e intracultural. Aunque hablemos en lengua castellana estamos abocados a traducir, a ejemplificar, a hablar en una lengua "más sencilla" o "más elaborada", acudimos a otra lengua popular o especializada, "correcta" o "parcera" para hacernos entender. En la comunicación oral o escrita, es menester el acto de la traducción.

"Las distintas lenguas que integran la semiósfera son asimétricas" ${ }^{3}$. Esto produce un diálogo constante y exégesis de los textos, por medio de su permanente traducción.

El caso más trivial es el del estudiante "práctico" que buscan en Internet en el "rincón del vago" el resumen de una novela del programa escolar; el más sofisticado el del estudioso de García Márquez o de José Eustasio Rivera que precisa hacer comentarios de pie de página en el texto de la novela y así comunicar los sentidos verbales, culturales, las alusiones, los guiños intertextuales desconocidos para un lector de otro tiempo. Las bibliotecas modernas están compuestas de miles de tomos de lo que se considera por los científicos, eruditos, educadores, o las instituciones culturales como la cultura universal o de Colombia. Estos textos son traducciones del inglés, del francés, del ruso o del griego clásico, del latín etcétera. Igualmente se traduce del inglés al español ibérico, (o se obliga a los estudiantes latinoamericanos de posgrado en las instituciones de España, a redactar "correctamente" sus tesis en el español peninsular).

En conclusión debe decirse que una biblioteca y sus lectores hacen parte de una particular semiosfera, en la que participan distintas lenguas ya sea modernas o clasicas; a su vez en una biblioteca se hallarían textos escritos en lengua castellana de los siglos XV, XVI o XX.

A la noción de mecanismo de traducción que explica la totalidad de la dinámica de la

2 Lotman explica este concepto en los tres volúmenes de sus "Artículos Escogidos", Tallin, 1992. Ver los artículos del primer tomo Semiótica de la cultura. О Семосфере, еn Избранные статьи, Талдин, Александра, 1992, Том 1, Стр. 11- 24.

3 La cultura es políglota en principio, y sus textos siempre se realizan en el espacio de por lo menos dos sistemas semióticos" «Культура в принципе полиглотична, и тексты ее всегда реадизуются в пространстве как минимум двух семиотических систем» Lotman, Iuri. El texto y el poliglotismo de la cultura, p.144. Tallin 1992. (En ruso). 
semiosfera, se añade la noción de "frontera", En una semiosfera hay un borde o frontera que distingue y transforma lo exterior de lo interior.

En el caso de las bibliotecas éstas funcionan como fronteras o líneas no materiales entre la semiosfera nacional y lo otro: el universo de lenguas, memorias, eventos que son referente de los libros de la biblioteca. Ya que buena parte de ellos está escrita en otras lenguas o son traducidos, la biblioteca funciona como frontera cultural de una sociedad dada, (para el caso del otro territorio cultural, la cultura audiovisual y sus mecanismos de difusión, esta frontera o fronteras culturales estará creada por la programación que ofrecen las distintas cadenas que ofrecen suscripción por cable)

Ilustra lo anterior la divisa de la actual Biblioteca de Alejandría, The new library of Alexandria, Bibliotheca Alexandrina. (http:// www.bibalex.org/aboutus/mission_en.aspx): "The world's window on Egypt. Egypts window on the world".

Las frases "La ventana del mundo hacia Egipto y la ventana de Egipto hacia el mundo" ilustran con claridad el sentido de frontera que constituye la dimensión esencial de una biblioteca. Los conjuntos de los libros de una biblioteca permiten al lector mirar hacia otra parte, salirse de sus límites culturales, espaciales y temporales, ingresar a otros territorios de saber, de subjetividad y de voluntad. La biblioteca es una suerte de mapa para el lector-intérprete de territorios imaginarios y físicos.

La frontera significa esencialmente, un borde cultural que permite la entrada a ciertos textos, una vez los significados o los textos son seleccionados, codificados y autorizados. La biblioteca como frontera de la semiósfera es un filtro.

El mundo exterior existe en la medida en que ha sido traducido, autorizado dentro de los códigos (Cuáles géneros, cuáles disciplinas, cuáles lenguas, cuáles autores, cuáles libros, cuáles códigos de interpretación, cuáles territorios culturales y cuáles épocas) de la biblioteca. Así, la biblioteca funciona como uno de los núcleos de la semiósfera que según Lotman está constituida por varios núcleos centrales y periféricos generadores de discursos y sentidos.

Constituyen estos núcleos las lenguas articuladas, visuales, los códigos plurales, las tensiones o conflictos entre la lengua escrita y la lengua oral, la lengua prestigiosa y la que no lo es, las lenguas del pasado o de la tradición, las lenguas clásicas vs las lenguas vulgares, los códigos esotéricos y los códigos populares, las memorias nacionales oficiales vs las memorias subalternas. Esta semiosfera con sus núcleos está en permanente tensión y vive permanentes pugnas de supremacía de una de las lenguas. (puede ser la tensión entre literatura clásica y literatura popular de folletines, entre textos escritos vs textos audiovisuales).

Así entonces las bibliotecas serán refugios de eruditos solitarios o escenarios de comunidades, de encuentro con múltiples destinatarios. La realidad de la función del libro no es homogénea, más bien resulta ser una red casi inabarcable.

En el siglo XXI, los libros pueden ser obras de arte únicas, ediciones con tirajes millonarios en papeles desechables, de mediana calidad, o con tirajes reducidos en materiales valiosos. Las Editio Prínceps, o primeras impresiones que vienen directamente de los manuscritos del autor. Estas ediciones tienen su valor no sólo por pertenecer a un autor consagrado, sino por la rareza de sus materiales, del año en que fueron impresas, de la calidad de su diseño tipográfico., constituyen verdaderas piezas únicas de colección. Alcanzan valores económicos inimaginables. Poseerlas significa un privilegio social y en Colombia la pertenencia a una élite cultural y económica. Los infolios son la primera edición de un libro considerado un clásico o una rareza ya sea por pertenecer a un autor excepcionalmente valorado o por corresponder a unas circunstancias específicas de impresión o de notoriedad temática.

"El infolio es esencialmente una maravillosa primera edición" (ver http://findesemana. libertaddigital.com/las-primeras-ediciones-noson-oro-1276231922.html) 


\begin{abstract}
"una casi perfecta primera edición de una obra de William Shakespeare. Se espera que alcance los 3,5 millones de libras (6,5 millones de dólares) cuando Sotheby's la subaste, el 13 de julio".
\end{abstract}

En relación con la consideración social sobre el valor de los libros raros de anticuarios de bibliotecas únicas, tendrá utilidad un concepto que puede caracterizar el espacio elitista y privilegiado de la biblioteca de un lector. En su clásico texto acerca de la obra de arte en la época de su reproductibilidad técnica, el filósofo $W$. Benjamin diferenciaba la obra con aura y aquella que era despojada de ésta. El aura era única, en relación con la tradición y con el ritual que creaba las condiciones de acceso a la obra, según Walter Benjamín: "Hoy nos parece que el valor cultual empuja a la obra de arte a mantenerse oculta". ("cultural", significa de culto") el valor "cultual" depende de la imposibilidad de reproducir masivamente una obra. Su exhibición masiva y reproducción elimina el "aura".

“En la época de la reproducción técnica de la obra de arte lo que se atrofia es el aura de ésta. Es proceso es sintomático; su significación señala por encima del ámbito artístico. Conforme a una formulación general: la técnica reproductiva desvincula lo reproducido del ámbito de la tradición. Al multiplicar las reproducciones pone su presencia masiva en el lugar de una presencia irrepetible. Y confiere actualidad a lo reproducido al permitirle salir, desde su situación respectiva, al encuentro de cada destinatario" ${ }^{\prime 4}$.

Esta interpretación sobre la nueva fase industrial cuando la reproducción masivae pone un texto al alcance de miles y desvaloriza su aura, corresponde a una nueva fase de la producción cultural. Cuando los textos resultan asequibles a millones, su soporte deja de ser único y su lenguaje traducible de modo comprensible. El texto ya no será literalmente intocable, o comprendido por una minoría experta, porque sus sentidos son susceptibles de amplia comunicación y reinterpretación.
En Colombia en el siglo XIX fue favorecida la noción que definía el valor cultural del libro por el atributo de su "aura", y por su condición de objeto "cultual" ("es de decisiva importancia que el modo aura-tico de existencia de la obra de arte jamás se desligue de la función ritual") es decir de su existencia única (de valiosa pieza única de exclusiva colección), de su significado asequible sólo a sus celosos propietarios, a una elite social e intelectual de lectores. La práctica previa a la modernidad condicionó la representación colombiana del libro, la biblioteca y el lector, moldeando los prejuicios y hábitos sobre los lectores y los libros en Colombia. Fue una reacción contra "la técnica reproductiva que desvincula lo reproducido del ámbito de la tradición". Esta actitud tuvo su influyente cultor en la figura de Nicolás Gómez Dávila.

\section{La biblioteca de un lector}

En Bogotá en las últimas décadas del siglo XIX y las cuatro primeras del siglo $X X$ se configuraría un tipo de lector y de biblioteca. El origen de una especie de lector con una relación específica hacia la biblioteca y la lectura, fue un proceso fascinante que acarreó el cambio de la semiosfera urbana y la pugna entre dos tipos de concepción de la lectura, el lector y la biblioteca.

Colombia estaba en estos años escasamente comunicada con fragmentadas vías férreas, en regiones aisladas y de pocas carreteras. Las únicas comunicaciones eléctricas eran las del telégrafo que unía a Bogotá con algunas capitales regionales; las comunicaciones telefónicas internacionales resultaron posibles hasta el año de 1930. Los contactos con el exterior solían ser los esporádicos viajes fluviales a Cartagena o Barranquilla surcando las inciertas aguas del río Magdalena, que a veces en tiempo de crecida caudalosa de las aguas o durante las sequías podían detener a los buques de hélice que llevaban a los viajeros a destinos inciertos en Europa, el Caribe o los EU. En los equipajes, baúles y maletas de estos aventurados e intrépidos viajeros llegaban los libros, medio 
de conocer lo que se pensaba, sucedía y vivía allende los mares. La formación de bibliotecas privadas estaba expuesta a los costos y riesgos que los viajeros enfrentaban navegando por las impredecibles corrientes del Magdalena, el río de la Patria.

En un texto que considero imprescindible, "Las viejas librerías de Bogotá" publicado en el mes de diciembre de 1937, en el boletín de la Academia Colombiana de Historia en Bogotá, se pueden hallar las claves culturales sobre la relación con los libros y la constitución del lector colombiano de finales y comienzos de los siglos XIX y XX. $\mathrm{Su}$ autor Laureano García Ortiz en vívida prosa precisa recrea un cuadro pintoresco y realista de la constitución de este lector y de su biblioteca ${ }^{5}$.

Es un texto que presenta a los lectores de aquella época como seres únicos que hicieron de su vida una acción lectora. No están por fuera de los azares de la economía, ni tampoco el autor del texto ofrece una visión dogmática sobre las bibliotecas, las librerías y los libreros. Es un detallado ensayo donde describe las concepciones sobre el libro como intercambio comercial e intelectual y narra a veces con humor y otras dramáticamente la relación de los lectores con sus bibliotecas:

"El doctor Rudas fue un hombre muy inteligente, muy ilustrado y de gran biblioteca. En ella fue encontrado muerto como Petrarca: sentado ante su mesa de trabajo, con la frente descansando sobre un volumen abierto"

La imagen del lector que muestra el fragmento, lo destaca como un personaje único de la talla de una figura del renacimiento italiano. El lector está por encima del vulgo: La muerte en el espacio de la biblioteca personal y única es significada como muerte distinguida; el libro "volumen" pareciera que recibiera el último respiro del lector confundiéndose así lector y texto. El retrato nos muestra a un ser humano cuya actividad de lector es exclusivamente intelectual sin efectos sociales evidentes. Aquí hay además una concepción sobre el texto como si este contuviera su sentido sin interpretaciones o traducciones posibles.

Los lectores evocados por García Ortiz, al hacer la historia de las librerías bogotanas, resultan héroes o villanos de vidas singulares.

Al hablar de la librería del general conservador Lázaro María Pérez que bautizó su librería con el nombre del escritor, lector y diplomático José María Torres, el autor del ensayo lo pinta así: "personaje de vida accidentada y pintoresca, arribista afortunado, que supo abrirse una carrera $y$ administrar su gloriola, con imperturbable paciencia y hábil reclamo. Comenzó por ser criado y luego familiar del ilustre arzobispo Mosquera; lo primero, le enseñó a ser dúctil y maleable; lo segundo, le enseñó el arte del ceremonial, las complicaciones del protocolo y las untuosas habilidades de los tratamientos".

Los lectores pueden llegar a convertirse en exitosos aventureros. Y la librería del general María Pérez rinde homenaje a un "arribista afortunado". Las anécdotas son reveladoras: los lectores se han convertido en particulares sujetos sociales con una función diferenciada, percibida por un agudo contemporáneo, como un atributo fundamental de la personalidad psicológica, social e intelectual de quien tomó la opción de ser lector.

El autor apunta a una especie de semiótica social al señalar como las librerías (la institución que por entonces sustituía a las bibliotecas públicas como proveedoras de textos para la sociedad), hacen parte de un espacio social y cultural, en donde ellas mismas son centros. Las librerías, negocios particulares, son la fuente que provee a las bibliotecas particulares. Son los núcleos generadores de una semiosfera. Dice Ortíz de la librería José María Torres "sin ella habríamos estado incomunicados con los países hermanos".

5 Las citas de García Ortiz, provienen del boletín de diciembre de 1937 de la Academia Colombiana de historia, compulsado por el autor de este artículo, en la Hemeroteca de la Biblioteca Nacional de Bogotá. 
Las principales librerías bogotanas de comienzos del siglo XX y hasta bien entrados los años treinta estaban localizadas en el centro político y social de Bogotá. Es decir, hacían parte del mismo e influían sobre él. El autor Laureano Ortiz escribe que tres de las cuatro librerías que suministraban "el alimento* intelectual requerido por Bogotá y por casi todo el país", estaban situadas en los "Legendarios Portales o antiguas Galerías de la Plaza de Bolivar". En la calle 12 que entonces se consideraba el corazón comercial de la ciudad, estaba la librería "del insigne don Miguel Antonio Caro". Este librero había sido Vicepresidente de Rafael Núñez.

Don Miguel Antonio Caro profesaba ideas ortodoxas y tradicionistas sobre la política, la sociedad y la cultura. Fue el redactor e inspirador con Rafael Núñez de la Constitución del 86. Su librería que abastecía a una minoritaria e influyente clientela (que de esta manera iba creando su biblioteca particular), en palabras de Laureano Ortiz, era "clásica, hispanófila, especialmente literaria $y$ estrictamente ortodoxa". Los libros escogidos por Don Miguel Antonio Caro tenían por propósito mantener como norma de uso lingüístico ${ }^{6}$ el español literario de autores españoles de los siglos XV y XVII. Miguel Antonio Caro además ofrecía a la venta documentos doctrinarios católicos y textos en latín.

Desde esta librería Caro propagaba una interpetación de lo europeo, el discurso de los clásicos latinos para una minoría que sabía el latín y consideraba distinguida, propia del "buen decir", cierta norma clásica castellana por oposición a los registros coloquiales, urbanas o regionales del habla colombiana. Esta librería funcionaba como una frontera o filtro cultural. Era la ventana de la cultura colombiana a una noción de la cultura europea, a una selección de la literatura peninsular y a la ortodoxia católica.

Los temas teológicos, la historia eclesiástica y la controversia religiosa, eran suministrados a los sacerdotes y lectores católicos del país por la librería del rector del Seminario de Bogotá, sacerdote Bernardo Herrera Restrepo. Era el núcleo radical católico que al lado de la librería americana de Caro daban forma a la semiosfera colombiana y a su entramado intelectual

Esta era una frontera semiótica que coexistía con la trazada por la exitosa y "disoluta" librería Barcelonesa de Soldevilla y Curriols. Ortiz expresa su repugnancia por la manera como la librería del catalán Curriols atraía a los lectores anónimos, integrantes de un incipiente mercado masivo urbano de libros y habitantes de la periferia de este mundo de librerías, bibliotecas y lectores devotos de la norma del catellano medieval y de los textos doctrinarios católicos y conservadores.

Mientras las otras librerías moldeaban a un lector latinista, hispanófilo de cepa, y proporcionaban "alimento espiritual" (resulta bien reveladora esta metáfora, la lectura se compara con el acto de comer, el acto de leer no es un proceso de intercambio social o de interpretación sino de transformación fisiológica), La librería Barcelonesa, "satisfacía los gustos pervertidos de los muchachos con apestosas pornografías".

“...el catalán Curriols sin criterio científico, ni moral, ni artístico, no era un verdadero librero profesional, profesión calificada desde tiempos antiguos entre las nobles, sino un mero comerciante de libros, que sin escrúpulos ni tapaditos satisfacía los gustos pervertidos de los muchachos, con las más apestosas pornografías. Así convertía la noble función social de fomentador e intermediario de las relaciones espirituales entre los hombres, en oficio rufianesco.

Una especialidad de la Barcelonesa eran sus pésimas traducciones. Libros originales de otras lenguas resultaban poco menos que desconocidos en las versiones españolas que propinaba a sus clientes la industria editorial

6 Sobre la concepción de Caro de la relación entre lengua y sociedad, ver Flórez Arcila: “Un Imperio Retórico de Cien Años", págs. 154-167 en Revista Palimpsestos, Facultad de Ciencias Humanas, UN Bogotá, 2001. 
peninsular. De seguro que eran traductores a destajo, a peseta el pliego, los míseros fautores de tanto estrago. Hasta los títulos de los libros los vertían con extravagancia grotesca. ¡Se les ocurrió que la Madame Bovary de Flaubert se llamara en español Adúltera!, y que la artística fantasía de Théophile Gautier, Mademoiselle de Maupin, se titulara ¿Hombre o hembra?, tan solo para hacerlos perversamente llamativos".

El primer cuestionamiento que hace García Ortiz, es que los textos vendidos en esta librería eran "pésimas traducciones". El asunto tiene que ver con el hecho de que los lectores a los que admira el autor Laureano García Ortiz y que aspiran a convertirse en auténticos lectores descreían de las traducciones. Es insistente la expresión "textos originales" para referirse al hecho de que una librería o un lector tengan "contacto con el verdadero pensamiento" sólo si lee una obra filosófica, científica o literaria en la lengua inicial en que fuera escrita. Tanto Miguel Antonio Caro como Laureano García Ortiz ven la biblioteca como un santuario donde se hallan los textos llamados por ellos "originales". Es decir, textos que no pueden ser traducidos. Su traducción los adultera. La traducción resulta así una copia infiel, que traiciona los sentidos originales, auténticos.

La execrada librería barcelonesa era la más exitosa de la ciudad de Bogotá en las décadas10 y 20 del siglo XX:

“Era la de comercio más activo en ese tiempo y atiborrada de ediciones de aparente lujo (tela roja ornamentada y cortes dorados) o francamente económicas (para el editor barcelonés no para el consumidor bogotano). En tales ediciones mediocres y bastante incorrectas, ponía al alcance de nuestros lectores poco exigentes, algunos de los libros consagrados por la cultura humana, pero al lado de ellos inundaba el mercado con producciones de una literatura barata, propagadora del peor gusto, capaz de inficcionar toda una generación. Novelas francesas folletinescas de Paul Feval, de Jonson du Terrail, de Xavier de Montepin, de Gaboriau".

Justamente, por las razones que el autor critica, es que considero que la librería Barcelonesa disfrutaba del éxito económico y del interés ávido que despertaba entre el público bogotano, y del cual no se puede desprender ni siquiera su crítico, el ameno escritor bogotano García Ortiz. En buena medida la Barcelonesa estaba creando una actitud urbana y moderna hacia el libro, masificando su intercambio, ofreciendo traducciones que tenían en cuenta los intereses y la mediana formación intelectual de los lectores, comunicando la producción cultural en otras lenguas.

La Barcelonesa estaba poniendo en circulación losformatos discursivos y narrativos que gozaron del éxito de los lectores urbanos europeos que no tenían exclusivamente intereses académicos o científicos. Es interesante ver como este tipo de masificación del libro tiene que ver con el surgimiento de una cultura popular letrada y urbana en Bogotá. Este formato de folletín, fue aprovechado hasta la década de los 30, por los periódicos bogotanos como El Tiempo y El Espectador, responsables en Bogotá de la expansión de una cultura urbana de masas letrada.

Es posible interpretar que la Barcelonesa, animada por un criterio de fortalecimiento en el mercado hiciera énfasis en crear nuevos lectores acercándolos a la producción literaria de su tiempo, con un discurso familiar y provocador para los incipientes lectores urbanos de las primeras décadas del siglo XX. Las nuevas tendencias de crítica a las relaciones sociales y familiares mostradas por la producción literaria europea de finales del siglo XIX, se ofrecían a través de traducciones acomodadas al discurso y las expectativas de información urbana de la clientela, con expresiones explícitas (y cuestionadas como de mal gusto lingüístico y moral por los lectores de elite de entonces que buscaban que los libros fomentaran "relaciones espirituales entre los hombres"). La novela del escritor francés Flaubert, Madame Bovary, era traducida como Adúltera, acaso para aumentar las ventas y seducir la curiosidad de los lectores de entonces que deseaban ver sus realidades representadas narrativa y discursivamente.

El autor García Ortiz, cuestiona el uso de expresiones provocadoras para la época, más 
a tono con las demandas de realismo social del lector urbano bogotano, que sobrelleva su existencia entre el tedio de los innumerables servicios religiosos de entonces.

En lugar de textos teológicos y los así llamados textos "originales" (por oposición a las traducciones que dogmáticamente eran consideradas copias por lectores como García Ortiz), esta librería divulgaba entre los lectores bogotanos, en cientos de ejemplares, autores que disfrutaban de gran acogida entre los habitantes de los grandes centros urbanos en Francia, Inglaterra, Rusia y México. Un autor cuyas obras en la segunda mitad del siglo XIX y en Bogotá hasta la primera década del siglo XX, gozó de las simpatías de sus lectores (tanto como las obras de Balzac y Victor Hugo) y cuyas novelas siguen reimprimiéndose hoy por hoy, fue el francés Paul Feval, autor de las primera novelas de detectives y de narraciones históricas escritas con ingenio, siguiendo las pautas de la novela por entregas o el género del folletín, (tal como las de Dumas).

Mientras los lectores de textos originales, en ediciones exclusivas debatían temas doctrinarias o se acercaban a los sentidos eternos o esenciales no "contaminados" por las traducciones y participaban en arduos debates teológicos o doctrinarios, los lectores de folletines y de novelas se acercaban a los temas escabrosos de la vida urbana bogotana: el surgimiento del "mezquino" individualismo burgués, el cuestionamiento de la visión católica hispánica, el afinamiento de las tácticas pequeñoburguesas de simulación, los conflictos entre estamentos, la aparición del hampa y la subsecuente curiosidad por sus protagonistas, la vida de concurrencia económica y social con sus avatares y las luchas concretas del poder en medio de la formación laica de la vida sentimental y las astucias sociales o la adopción de máscaras para sobrevivir en una sociedad de incipiente mercado urbano (nada que ver con el libro como "fomentador de las relaciones espirituales entre los hombres" como se lamentaba García Ortiz.

Literatura de folletín (para su tiempo un contenido moderno y pragmático) en traducciones puestas al nivel del público, era lo que vendía la librería Curriols, contribuyendo así a formar otro tipo de biblioteca y de lector. Su editor es calificado por García Ortiz como un "rufián", pero el éxito comercial de esta librería muestra un conocimiento del mercado de los libros y la intuición sobre los lectores urbanos que traía a Bogotá de Barcelona. Esta librería es descalificada por que los textos que divulgaba entre sus lectores eran "literatura barata, propagadora del peor gusto". Las traducciones provocaban "la adulteración, la mutilación y el estropeo del texto" según escribía Laureano García Ortiz en diciembre de 1937.

Este tipo de actitud hacia los "Infieles" textos traducidos que impedían al lector aproximarse a las obras en sus "textos originales", actitud que desvalorizaba la traducción, componente fundamental de la comunicación de una biblioteca, trajo como consecuencia, o como reacción de rechazo, otro tipo de lector que despreció las traducciones y que convirtió en una especie de refinamiento aristocrático e intelectual el desdén por los textos escritos en español por autores contemporáneos. El tipo que ilustra esta evolución hacia un lector de significados no pervertidos por la traducción, hacia una biblioteca sin comunicación con otro lector como no fuera con el poseedor del "código esotérico", de conocedor de la lengua inicial del texto "auténtico" en su primera versión y no traducido, (el libro con aura), fue Nicolás Gómez Dávila. La biblioteca de Gómez Dávila estaba constituida exclusivamente por raras primeras ediciones de obras "clásicas" en lenguas extranjeras.

Se trataba de la biblioteca de un lector. Tres rasgos caracterizan a este lector y su biblioteca. La convicción de que sólo es posible una lectura que no corrompa los sentidos de un texto, profunda si se lee el texto en la lengua inicial en que fuera escrito. La segunda es el cultivo de un fetichismo por la edición primera antigua y de un status de exclusividad al ser propietario de ediciones príncipes, o primeras ediciones. La tercera es la negación de la traducción como medio de comunicación e interpretación de un texto escrito en una lengua extranjera. 
Gómez Dávila un comerciante acaudalado de Bogotá, consagró su ocio a la lectura de textos no traducidos. Para Gómez D. el oficio de lector consistía en la exégesis que reitera sin transformarlos los sentidos inmutables de los textos clásicos. Su vida como coleccionista de libros evoca la figura de Jorge Burgos el monje bibliotecario de la abadía escenario donde transcurre El nombre de la Rosa de U. Eco. Su insistencia en que frente a los textos sólo es posible la opción del "escolio" que reitera, lo hace alter ego colombiano del bibliotecario, personaje de la pugna entre modernidad y medioevo, narrada en la novela del semiólogo Umberto Eco.

Los libros de su biblioteca, seleccionada lo largo de su vida, son piezas aura-ticas, irrepetibles, únicas como las obras de arte anterior a la era de la reproductibilidad técnica tal como las definiera W. Benjamin: "al multiplicar sus reproducciones pone, en lugar de su aparición única, su aparición masiva".

Y como comenta un investigador de dicha colección, en la biblioteca del exclusivo lector y coleccionistas de libros raros que era Gómez Dávila se encontraban:

"las mejores ediciones posibles (no siempre las primeras) en sus idiomas originales (no creía en las traducciones). Por ello, no es difícil encontrar libros en griego, latín, italiano, alemán, portugués y francés (su idioma preferido)

La literatura estaba presente con la obra completa en espléndidas ediciones príncipes de autores como Cervantes, Lope de Vega, Shakespeare, Víctor Hugo, Paul Valéry, Marcel Proust, Stephan Mallarmé, Julio Verne, Bertolt Brecht, Thomas Mann y James Joyce. De literatura latinoamericana no poseía casi nada, ninguno de los autores del boom estaba representado, ni siquiera García Márquez. Sólo dos libros de Cortázar y dos de Borges" ${ }^{\prime 7}$.
Gómez Dávila, quien viviera hasta las últimas décadas del siglo pasado, sostuvo reiteradamente la convicción de que la comunicación (traducción o comentario, o divulgación) resulta inútil, vana e innecesaria:

"El símbolo susceptible de traducción carece de importancia ${ }^{8 \prime}$

Es decir, un texto si resulta traducido no posee valor intelectual. Si un texto es traducible: "susceptible de traducción", no merece su lectura.

Por símbolo debemos entender según el autor, los textos de los filósofos de su predilección, ciertas obras "clásicas" de la literatura. Estos textos no pueden ser comentados, traducidos ni divulgados. Es por ello que el autor ridiculizaba cualquier propósito de traducción o de comentario.

La explicación, la refutación, la producción de un nuevo sentido están descartadas en citada afirmación de Gómez Dávila.

Con Gómez Dávila la historia en Colombia del lector, el libro, las bibliotecas y la traducción se corresponde con una determinada práctica y representación que considera al lector como a un ser aislado en su biblioteca de textos únicos e intraducibles. Esta biblioteca está constituida por textos excepcionales con aura. Textos únicos, no susceptibles de ser traducidos a otra lengua, en este caso el idioma español o a otros textos que los comenten, cuyos significados permanecen inmutables y sólo pueden ser apropiados por su lector a través de una comunicación esotérica y mística. Esta biblioteca y este lector descartan la posibilidad de la traducción a otra lengua y a otro lector.

Tal idea de biblioteca, de lector y del libro hace parte de una representación que influyó profundamente la noción de libro, lector y biblioteca en la cultura colombiana.

7 Quesada Halin Badui. En apuntes para una biblioteca imaginaria. Revista Interamericana de Bibliotecología. Medellín, junio de 2007.

8 Gómez Dávila, 1992, 25. 


\section{Lectores de bibliotecas}

Ya en los tiempos en que fueron abiertas las primeras librerías que contribuyeron a la formación de un número considerable si bien escaso de lectores en Bogotá, y a la formación de las primeras bibliotecas particulares, los lectores, los libros y las librerías estaban ubicados dentro de una suerte de flujo de comunicaciones, económico y de comunidades lectoras.

Las primeras librerías de las primeras décadas del siglo XIX estuvieron situadas en lugares de gran intercambio cultural y comercial, como relata el ya citado Gómez Ortíz: "La librería Americana, la del insigne Miguel Antonio Caro, era otra de las que funcionaban en ese entonces, en un local que ya no existe, en la calle 12, amplio almacén en los bajos de la casa que fue de don Aurelio Paris, luego del Gun Club, más tarde de la compañía colombiana de seguros y hoy magnífico edificio de almacenes y oficinas uno de los que sonn propiedad de Camacho Roldán y Cía".

Hacían parte de redes donde se movilizaban e intercambiaban significados, mercancías, servicios y se traducían, aún con la resistencia de quienes, con una actitud cultural influyente, desconfiaban del intercambio masivo, de la traducción y de la comunicación amplia, extensa a otras lenguas. Sin embargo, los lectores, los textos y las bibliotecas por su misma naturaleza no pueden escapar a su ontología o realidad cultural intrínseca, son textos para el intercambio y la interpretación.

El hecho de que las primeras librerías y los primeros lectores concurrieran en los espacios bogotanos que reunían la mayor circulación de discursos, servicios y mercancías, como Los Portales en la plaza de Bolivar y la calle 12, no significa otra cosa sino que las bibliotecas primeras que se constituyeron y que contribuyeron a formar la función especializada del lector, estaban inmersas en una dinámica de la semiosfera de encuentro de lenguas, de transformaciones de los códigos y de sus luchas, la lengua traducida vs la lengua del original, los significados inmutables de los textos doctrinarios vs el realismo acomodaticio y pragmático de los personajes individualistas, urbanos y con sucesivas personalidades enmascaradas presentes en las populares novelas de folletín de Paul Leval.

La convicción de que los textos pueden contribuir al cambio cultural como lo fuera el programa cultural de la Librería Colombiana del doctor Camacho Roldán o que los libros portadores de excelsos significados sustentan el mundo, y que los textos solo pueden ser parafraseados y no comunicados según el principio de Nicolás Gómez Dávila, eran dos formulaciones sobre el lugar de la lectura, los libros y las bibliotecas. Estas concepciones estaban en pugna.

La pugna entre la biblioteca para un lector de libros incunables que lee la lengua de símbolo inefable del texto primero "auténtico" pero que descree de la comunicación y la traductibilidad y entre aquellos partidarios de concebir los libros y la lectura como vehículos de modernización y creación de nuevos sentidos que pueden favorecer el cambio cultural: "El doctor Camacho Roldán al fundar la Librería Colombiana quiso que los estudiosos de su país pudieran beber en sus propias fuentes el pensamiento filosófico universal, que formaran su propio criterio leyendo a Bacon, a Spinoza y Leibnitz, a Kant y Hegel", "la Librería Colombiana puso al alcance de su clientela, con amplio pero sesudo discernimiento, los mejores frutos de la cultura moderna"

El sentido social de la actitud elitista en relación con los libros y la lectura, fue profundamente criticado desde la prensa bogotana en la década del treinta por autores, periodistas y ensayistas como Germán Arciniegas y sobre todo Darío Echandía quienes impulsaron durante el primer gobierno de Lopez Pumarejo un ambicioso programa de masificación de los libros. Fue durante el gobierno de Enrique Olaya Herrera en 1934, hacia el final de su mandato que se inició el proyecto de construcción de la Biblioteca Nacional de Colombia, inaugurada por el gobierno de la primera administración de López Pumarejo. 
Esta tendencia de identificación de los lectores con una semiósfera o espacio cultural fluido en una frontera que va y viene, en un flujo de semiosis ${ }^{9}$ de una a otra lengua, de un universo de sentidos a su traducción en distintas lenguas y a la creación de nuevos sentidos, escribe Lotman en su texto sobre la semiosfera: «Таким образом, семиосфера многократно пересекается внутренними границами, специализирующими еe участки в семиотическом отношении». Esto se manifiesta con claridad en el hecho de que las modernas bibliotecas son sobre todo una realidad especializada, fluida, comunicada incesantemente, traducida, en movimiento que aspira a contener todos los libros.

El urbanismo actual y el diseño de las ciudades conciben las bibliotecas como núcleos de encuentro. Están construidas en medio de encrucijadas de vías, autopistas. No se encuentran en lugares aislados, inaccesibles o solitarios. La realidad urbana como una dinámica intensa de comunicación ya sea material o virtual, ha hecho que las bibliotecas y los lectores nos hallemos en una semiósfera de flujo virtual y material. Los textos de la biblioteca buscan aumentar su número de lectores y expandir su presencia a través de la generación de nuevos sentidos en sus lectores. La biblioteca es una frontera en constante apertura hacia el mundo del lector, el universo de la imaginación humana en el espacio sin tiempo físico de la invención intelectual, el mundo plural de la ciudad, y el lugar donde los sentidos del texto están en permanente traducción y comunicación para lectores iniciales e iniciáticos.

La biblioteca y sus lectores transforman los sentidos y los textos de la cultura del pasado y los traducen a los heteróclitos lenguajes de la semiosfera del presente. Al mismo tiempo los reformulan y renuevan. Es el reto de todos los que amamos los libros, la lectura y la biblioteca: Traducir la biblioteca a todos los lenguajes de la semiosfera y dejar en el museo como un aurático y clasista objeto cultural la biblioteca para un lector.

\section{Referencias bibliográficas}

Borges, J.L. (2000). La Biblioteca de Babel. Buenos Aires: Editorial Emecé.

Benjamin, W. (2003). La obra de arte en la época de su reproductibilidad técnica. México: Editorial Ítaca.

(1989). Discursos Interrumpidos.

Buenos Aires: Taurus.

Eco, U. (1999). La estructura ausente. Barcelona: Lumen.

García O. L. (1937). Las viejas librerías de Bogotá. Boletín de la Academia Colombiana de Historia. Bogotá: Academia Colombiana de Historia.

Gómez Dávila, N. (1992). Sucesivos escolios a un texto implícito. Bogotá: Instituto Caro y Cuervo, serie "La granada entreabierta".

Badui-Quesada, H. (2007). Apuntes para una biblioteca imaginaria: valor patrimonial y situación legal de las bibliotecas de Bernardo Mendel y Nicolás Gómez Dávila. Revista Interamericana de Bibliotecología, Vol. 30, No. 1 (ene.-jun.) p. 167-184.

Lotman, Iuri. (1992). О семиосфере. Избранные статьи, Талдин,Александра, т.I, Стр. 11-24.

9 Para determinar lo que es el interpretante de un signo, hay que denominarlo con otro signo, el cual a su vez tiene un interpretante denominable por otro signo, y así sucesivamente. Aquí se produciría un proceso de semiosis ilimitada" Eco, 1999, 73. 